\title{
Vidas desfeitas e vidas refeitas: novas reflexões sobre a experiência escrava no comércio interno de cativos
}

Joice Oliveira[1]

\section{PARGAS, Damian Alan. Slavery and forced migration in the antebellum south. New York: Cambridge University Press, 2015. 281 p.}

\begin{abstract}
migração interna e forçada de escravos não é novidade nos estudos dedicados à escravidão. Há algumas décadas, os historiadores têm 1 movido esforços com o intuito de compreender os aspectos, sobretudo políticos, econômicos e demográficos, concernentes ao comércio interno de escravos. Nessa empreitada, temas como o número e o perfil dos indivíduos negociados, as formas e os envolvidos na organização comercial, os determinantes da oferta e demanda de mão de obra cativa e os debates em torno da legalidade daquele comércio figuram como centrais em pesquisas recentes. No entanto, a perspectiva dos escravos em relação à experiência vivida nesse comércio e a posterior reconstrução de suas vidas ainda permanecem
\end{abstract} lacunares na produção acadêmica.

No que concerne à historiografia norte-americana, é notável que historiadores como Michael Tadman (1989), Walter Johson (1999), Steven Deyle (2005) e Robert Gudmestad (2003) tenham se concentrado no comércio interno de escravos no sul dos Estados Unidos no período anterior à Guerra Civil. Essa historiografia perscrutou a extensão e a organização do comércio interno, bem como seus efeitos, sobre os proprietários, negociantes e escravos. Ela indagou sobre o cotidiano daqueles que aguardavam a venda nos mercados de cativos e sobre o impacto daquela atividade na formação da jovem nação norte-americana. E, mais ainda, inquiriu sobre como os negociantes, o comércio interno e a própria escravidão foram vistos pela sociedade ao longo do tempo. Contudo, tais estudos não tinham por propósito privilegiar a percepção escrava diante da violência de serem comercializados. A exceção ocorre com Heather Andrea Williams (2012), que, por meio de uma proposta analítica distinta, investiga os sentimentos e as ações de escravos que foram separados de seus familiares pelo comércio interno e passaram parte de suas vidas tentando reencontrá-los.

Resenha recebida em 2 de maio de 2016 e aprovada para publicação em 20 de maio de 2016.

[1] Doutoranda pelo Programa de Pós-graduação em História Social da Universidade Estadual de Campinas - Brasil.

E-mail: oliveira.joicef@gmail.com 
É justamente a partir desse cenário historiográfico que o historiador holandês Damian Alan Pargas circunscreve seu objeto de pesquisa: Slavery and forced migration in the antebellum south é o resultado de uma minuciosa investigação realizada nos arquivos norte-americanos e tem o objetivo de trazer à tona a experiência dos indivíduos subjugados ao comércio interno. Pargas revela as percepções escravas diante de cada etapa do processo de comercialização de suas vidas, incluindo o período de adaptação do forasteiro à nova realidade. Para tanto, o autor se debruça sobre uma vasta série documental, focando tanto as narrativas cativas quanto as entrevistas de ex-escravos e refugiados nos estados do norte estadunidense e no Canadá. A pesquisa recorre, ainda, aos registros e memórias de senhores de escravos, aos diálogos entre cativos e viajantes, aos anúncios de escravos fugidos e a registros oficiais referentes à população escrava.

\section{Como os escravos vivenciaram as diversas formas de migração forçada ao longo do século XIX?}

Nesse intento, a advertência metodológica inicial de Pargas é notável. Apesar de a historiografia comumente sinonimizar comércio interno e comércio interestadual, é necessário, segundo o autor, diferenciar três tipos de migração forçada: a de longa distância (interestadual), a local e a urbana. Essa classificação se sustenta na justificativa de que a quantidade de milhas percorridas impactava diretamente as reações e as possibilidades futuras dos escravos. Exatamente apoiado nessa distinção, o historiador engendra uma análise comparativa da experiência de cativos nascidos nos Estados Unidos, contrastando e assemelhando a trajetória daqueles que enfrentaram o comércio de longa distância com a de outros, que vivenciaram o comércio local e urbano.

Como os escravos vivenciaram as diversas formas de migração forçada ao longo do século XIX? O que eles sabiam sobre esse comércio e como tentaram resistir ou negociar os termos de sua remoção? Em que medida esses escravos foram capazes de se adaptar às novas comunidades, ao novo regime de trabalho e à nova relação senhor-escravo? Como se caracterizava a relação dos forasteiros com outros cativos? Em que medida o comércio interno contribui para o desenvolvimento de identidades escravas mais amplas? Essas são algumas das perguntas elaboradas por Pargas, que, concomitantemente, compõem a estratégia metodológica e narrativa do livro, bem como fomentam novas reflexões compatíveis não apenas com o contexto norte-americano, mas também com outros lugares, nos quais o comércio interno de seres humanos foi uma realidade.

O livro está dividido em duas partes, "Migração" e "Assimilação". A primeira, como sugere o título, acompanha as várias etapas do movimento migratório de pessoas pertencentes à chamada "migration generations" - cativos 
americanos que viveram entre a Guerra Revolucionária (1775-1783) e a Guerra Civil (1861-1865). Esse movimento obrigou milhares de escravos a cruzarem as fronteiras do Upper South em direção ao Lower South, bem como o deslocamento de outros numerosos cativos dentro de um mesmo estado. Por vezes ainda, a sina foi dupla, uma vez que, em alguns casos, os escravos foram submetidos a ambos os percursos.

É precisamente ao exame das causas dessa onda migratória e à avaliação das diferentes formas de organização do comércio que o primeiro capítulo do livro se dedica. No que se refere ao comércio interestadual, Pargas observa que parte das negociações no período entre 1820-1860 pode ser explicada por fatores relacionados com o declínio e a ascensão produtiva de culturas distintas no país. Mais especificamente, o comércio de pelo menos 875 mil escravos estaria relacionado com o declínio na produção de tabaco em estados como Maryland e Virginia (Upper South) e o vertiginoso crescimento da produção de algodão e açúcar em estados como Texas, Alabama, Mississipi e Louisiana (Lower South) - que, juntos, importaram 75\% dos escravos. O aumento da demanda pela mão de obra escrava e a consequente elevação dos preços nas áreas em expansão econômica atraíram o interesse de senhores das regiões em decadência, que enxergavam na venda de seus cativos uma possível solução para seus problemas. Por sua vez, no que concerne às migrações locais, Pargas as classifica como permanentes ou temporárias. No primeiro caso, elas eram decorrentes da imprevisível situação financeira dos senhores, que podiam rapidamente enriquecer e migrar em busca de novas terras - carregando consigo seus escravos - ou falir e negociar seus cativos para pagar as dívidas. Já as migrações temporárias eram o resultado da locação de escravos para trabalharem em propriedades agrícolas no interior do estado ou nos centros urbanos por determinado período.

Diante da iminência da comercialização, os escravos lutaram para preservar, acima de tudo, a unidade familiar. Para isso, negociaram os termos de sua remoção, apelaram para a consciência de seus senhores e, quando nada funcionou, cometeram atos como fuga, ataque contra senhores, automutilação, infanticídio e suicídio. Esse protagonismo é o tema do segundo capítulo, cujo argumento central versa sobre o modo como as reações escravas variavam conforme o tipo de comércio, o conhecimento sobre o local de destino e, principalmente, o impacto da migração sobre as famílias. À vista disso, Pargas afirma que se, por um lado, havia poucas chances de evitar as separações familiares no comércio interestadual, por outro os escravos comercializados no mercado local e urbano podiam ser mais bem-sucedidos, principalmente quando se encarregaram de encontrar seus próprios compradores na vizinhança ou negociaram diretamente com os compradores nos leilões e nos mercados.

A venda era o primeiro passo rumo a uma jornada que poderia se estender de acordo com o destino e a organização do comércio. Segundo essas circunstâncias, Pargas perscruta, ao longo do terceiro capítulo, o modo como os 
escravos viveram e sentiram cada etapa do processo de remoção. Para o autor, a experiência mais difícil foi a dos escravos do comércio interestadual, que, privados de comida e descanso, acorrentados e maltratados pelos negociantes, eram obrigados a marchar durante semanas pelos rincões do Lower South até chegarem aos mercados, onde eram confinados em celas e dali só saíam para uma nova e penosa caminhada, dessa vez em direção à sua futura morada. Apesar de o percurso geralmente ser mais curto para os comercializados no mercado local e urbano, Pargas ressalta que eles também sofriam as humilhações de serem tratados como mercadorias, principalmente durante a avaliação física realizada pelos potenciais compradores, momento que era particularmente cruel para as mulheres, frequentemente abusadas sexualmente.

\section{O aumento da demanda pela mão de obra escrava e a consequente elevação dos preços nas áreas em expansão econômica atraíram o interesse de senhores das regiões em decadência}

Terminada a remoção, uma complicada fase começava na vida daqueles indivíduos: a assimilação. Assim que adentravam a nova propriedade, os escravos se tornavam forasteiros e eram compelidos a se adaptar à nova realidade, dentro da qual o trabalho tinha importância primordial. Ciente disso, Pargas se indaga no quarto capítulo sobre como a mudança de ocupação promoveu dificuldades e/ou oportunidades para os recém-chegados. Segundo o historiador, os escravos oriundos de outros estados encaravam as maiores adversidades, uma vez que o processo de aprendizado do trabalho poderia ser extremamente penoso, especialmente se ocorria durante a colheita do algodão ou do corte da cana-de-açúcar. Pargas acrescenta ainda que, tanto na esfera doméstica quanto nos centros urbanos, os escravos podiam usufruir de algumas vantagens, como melhor alimentação e vestuário, no caso dos que viviam na casa-grande, e maior mobilidade e menor vigilância, para os que viviam nas cidades. No entanto, Pargas salienta que, apesar do entusiasmo de muitos escravos, que enxergavam na vida fora da lavoura a oportunidade de uma vida melhor, dividir o teto com seus senhores ou trabalhar nas indústriass podia ser ainda mais degradante.

No capítulo seguinte, o autor examina em que medida a relação com os senhores/feitores e as condições materiais dos escravos foram alteradas com a migração forçada. Segundo ele, apesar de o tratamento recebido pelos recém-chegados às lavouras no Lower South variar conforme o tamanho da propriedade e com a presença ou o absenteísmo dos senhores, as reclamações referentes à falta de alimentação, vestuário e moradia adequada eram comuns. Além da precariedade material, os recém-chegados eram mais suscetíveis às punições. Nas lavouras, eram castigados principalmente por erros 
relacionados com o trabalho, e nos centros urbanos sofriam por infringir códigos de comportamento com os quais não estavam familiarizados.

Após acompanhar a experiência dos escravos durante a remoção e a adaptação à nova realidade, Pargas finaliza seu livro estudando o esforço empreendido pelos forasteiros para se integrarem à nova comunidade e reconstruírem suas vidas. Nesse intento, o autor problematiza a noção de comunidade escrava monolítica e a existência de uma coesão entre os escravos capaz de garantir a fácil interação (Berlin, 2003). Para o autor, as diferenças de idioma, sotaque, religião, costumes e, até mesmo, o chauvinismo regional eram obstáculos significativos à integração entre os recém-chegados e os antigos moradores. De acordo com o historiador, os escravos submetidos ao comércio interestadual manifestaram a chamada dupla orientação, fenômeno que combinava o desejo de voltar para seus antigos lares com a necessidade de se integrar à nova condição de sobrevivência. Diante desse imbróglio, encontraram na criação de laços familiares uma chance para o recomeço e nas histórias contadas a seus filhos uma esperança de manter viva a memória de um lar e tempo pretérito.

\section{Além da precariedade material, os recém-chegados eram mais suscetíveis às punições}

Por meio de uma escrita fluida e cativante, Damian Alan Pargas tece uma consistente análise historiográfica alinhavada às fontes históricas, que, além do mérito de investigar a experiência dos escravos em cada etapa da migração forçada, vai ainda mais longe, ao perscrutar o processo de adaptação e integração dos recém-chegados às novas comunidades, e isso narrado, cuidadosamente, a partir da percepção escrava. No entanto, algumas ressalvas são necessárias.

Apesar de insistir nas distinções entre os tipos de comércio interno, Pargas dedica a maior parte de sua pesquisa à experiência dos que viveram o comércio interestadual, tornando a narrativa, por vezes, um pouco repetitiva. E, em alguns momentos, as diferenças entre a vivência no comércio local e urbano parecem muito tênues. Ademais, ao considerar a família como parte essencial do processo de adaptação e integração dos escravos, o autor se concentra, basicamente, no casamento, negligenciando a importância da família extensa (Malone, 1992). Ainda sobre o aspecto familiar, o autor não avalia que a integração dos escravos poderia ocorrer de maneira diferente em propriedades recém-formadas e em propriedades estabelecidas de longa data, ou seja, naquelas em que a comunidade escrava tinha alto grau de consolidação das redes de parentesco e solidariedade. Nesse segundo caso, as chances de inserção do forasteiro poderiam ser limitadas. E, no que diz respeito às propriedades de formação recente, em que havia poucos núcleos familiares e a 
maioria dos escravos era composta por homens adultos e solteiros, as possibilidades de constituir famílias e criar uma rede de parentesco poderiam ser ainda menores.

Não obstante tais considerações, por fim cabe enfatizar que as contribuições promovidas por Pargas extrapolam a historiografia americana e podem encorajar novas pesquisas sobre o comércio interno de escravos em outras localidades, inclusive no Brasil. Embora a historiografia brasileira se dedique a essa temática desde 1970 e já tenha realizado importantes avanços na compreensão da dinâmica daquela atividade, ${ }^{2}$ pouco se sabe sobre seu impacto na vida dos cerca de 400 mil escravos comercializados no império brasileiro após o fim definitivo do tráfico atlântico de africanos. Diante dessa lacuna, alguns historiadores e historiadoras têm direcionado suas atenções para os locais de saída do comércio interestadual com o objetivo de compreender o modo como eles reagiram à ameaça da venda e da provável dissolução familiar. ${ }^{3}$ Mas, ainda assim, os estudos dedicados à experiência durante a migração, adaptação e integração dos cativos nos locais de chegada são muito escassos. ${ }^{4}$ Nesse cenário historiográfico, as questões investigadas por Pargas podem incentivar novas buscas nos arquivos brasileiros, que se, por um lado, não guardam dezenas de biografias de escravos, por outro estão abarrotados de registros de batismo e de casamentos, processos-crimes, registros de meia-siza, procurações e tantos outros documentos que, uma vez correlacionados, podem contar sobre como viveram, sentiram e reagiram aqueles que foram submetidos à violência do comércio interno.

2 Para citar alguns: Neves (2000), Slenes (2004), Motta, (2012) e Scheffer (2012).

3 Para citar alguns: Mattos (1998), Pires (2009) e Ferreira Sobrinho (2011).

${ }^{4}$ Algumas exceções são: Machado (1987), Rocha (2004) e Oliveira (2013). 


\section{Referências bibliográficas}

BERLIN, Ira. Generations of captivity: a history of African-American slaves. Cambridge, Mass.: Harvard University Press, 2003.

DEYLE, Steven. Carry me back: the domestic slave trade in American life. Nova York: Oxford University Press, 2005.

FERREIRA SOBRINHO, José Hilário. "Catirina, minha Nêga, tão querendo te vende..." Escravidão, tráfico e negócios no Ceará do século XIX (1850-1881). Fortaleza: Secult/CE, 2011.

GUDMESTAD, Robert. A troblesome commerce: the transformation of the interstate slave trade. Baton Rouge: Louisiana State University Press, 2003.

JOHSON, Walter. Soul by soul: life inside the antebellum slave market. Cambridge, Mass.: Harvard University Press, 1999.

MALONE, Ann Patton. Sweet Chariot. Slave family and householf structure in nineteeth-century Lousiana. Chapell Hill: University of North Carolina Press, 1992.

MATTOS, Hebe Maria. Das cores do silêncio: os significados da liberdade no sudeste escravista, Brasil século XIX. Rio de Janeiro: Nova Fronteira, 1998.

MOTTA, José Flavio. Escravos daqui, dali e de mais além: o tráfico interno de cativos na expansão cafeeira paulista (Areias, Guaratinguetá, Constituição/Piracicaba e Casa Branca, 19611887). São Paulo: Alameda, 2012.

NEVES, Erivaldo. Sampauleiros traficantes: comércio de escravos do alto do sertão da Bahia para o oeste cafeeiro paulista. Revista Afro-Ásia, Salvador, n. 24, 2000.

OLIVEIRA, Joice Fernanda de Souza Oliveira. Forasteiros no oeste paulista: escravos no comércio interno de cativos e suas experiências em Campinas, 1850-1888. Dissertação (Mestrado em História), Unicamp, Campinas, 2013.

PIRES, Maria de Fátima Novaes. Fios da vida: tráfico interprovincial e alforrias nos Sertoins de Sima - BA (1860-1920). São Paulo: Annablume, 2009.

ROCHA, Cristiany Miranda. Gerações da senzala: famílias e estratégias escravas no contexto dos tráficos africano e interno, Campinas, século XIX. Tese (Doutorado em História), Unicamp, Campinas, 2004.

SCHEFFER, Rafael da Cunha. Comércio de escravos do sul para o sudeste, 1850-1888: economias microrregionais, redes de negociantes e experiência cativa. Tese (Doutorado em História), Unicamp, Campinas, 2012.

SLENES, Robert. The Brazilian internal slave trade, 1850-1888: regional economies, slave experience and the politics of a peculiar market. In: JOHNSON, Walter (Ed.). The chattel principle: internal slave trade in the Americas. New Haven: Yale University Press, 2004. p. 325-370.

TADMAN, Michael. Speculators and slaves: masters, traders and slaves in the old south. Madison: University of Wisconsin Press, 1989.

WILLIAMS, Heather Andrea. Help me to find my people: the African American search for family lost in slavery. Chapell Hill: University of North Carolina Press, 2012. 